\title{
BMJ Open Hyperuricaemia and associated factors among the oldest-old population in the urban areas of Chengdu, China: a community-based cross-sectional study
}

\author{
Xiang-Ji Chen, ${ }^{1}$ Wenqiang Zhang, ${ }^{2}$ Rui-Li Yuan, ${ }^{3}$ Xiao-Bo Huang (D) , ${ }^{4}$ Ya Liu, ${ }^{5}$ \\ Rong-Hua $\mathrm{Xu}^{6}{ }^{6}$ Dong Wei, ${ }^{5}$ Wei-Wei Tang ${ }^{7}$
}

To cite: Chen X-J, Zhang W, Yuan R-L, et al. Hyperuricaemia and associated factors among the oldest-old population in the urban areas of Chengdu, China: a community-based crosssectional study. BMJ Open 2021;11:e055881. doi:10.1136/ bmjopen-2021-055881

- Prepublication history and additional supplemental material for this paper are available online. To view these files, please visit the journal online (http://dx.doi.org/10.1136/ bmjopen-2021-055881).

X-JC and WZ contributed equally.

Received 28 July 2021 Accepted 27 October 2021

Check for updates

(c) Author(s) (or their employer(s)) 2021. Re-use permitted under CC BY-NC. No commercial re-use. See rights and permissions. Published by BMJ.

For numbered affiliations see end of article.

Correspondence to Dr Xiao-Bo Huang; drhxiaobo@163.com and Dr Wei-Wei Tang;

homertang@njmu.edu.cn

\section{ABSTRACT}

Objectives To investigate the prevalence of

hyperuricaemia among the oldest-old persons in Chengdu and identify associated factors to provide information on achieving healthy ageing in China.

Design

A community-based cross-sectional study.

Setting Jinjiang, Qingyang, Longquanyi locating in the southeast, the northwest and the east of Chengdu, respectively, were chosen as the study sites.

Participants A representative sample of 1391 people aged over 80 years were enrolled from September 2015 to June 2016, and 106 participants were excluded due to missing information. Thus, a total of 1285 participants were analysed in this study.

Outcome measures Hyperuricaemia was defined as serum uric acid $>420 \mu \mathrm{mol} / \mathrm{L}$ in men or serum uric acid $>360 \mu \mathrm{mol} / \mathrm{L}$ in women. A univariable logistic regression model and a multivariable logistic regression model were used to estimate the ORs and $95 \% \mathrm{Cl}$ to explore the associated risk factors of hyperuricaemia. Results The overall prevalence of hyperuricaemia among the oldest-old was $29.6 \%$. There was no significant sex difference in the prevalence of hyperuricaemia, 29.1\% in men vs $30.0 \%$ in women ( $p>0.05$ ). Hyperlipidaemia and overweight were associated with the risk of hyperuricaemia both in men $(0 \mathrm{R} 1.86 ; 95 \% \mathrm{Cl} 1.27$ to 2.72; $\mathrm{OR} 2.44 ; 95 \% \mathrm{Cl} 1.42$ to 4.19$)$ and in women (OR $1.78 ; 95 \% \mathrm{Cl} 1.23$ to 2.58 ; OR $2.95 ; 95 \% \mathrm{Cl} 1.89$ to 4.61 ). Additionally, diabetes mellitus was associated with an increased prevalence of hyperuricaemia only in women (OR 1.99; 95\% Cl: 1.34 to 2.97).

Conclusion The burden of hyperuricaemia is substantial among the oldest-old population in the urban areas of Chengdu, China.

\section{INTRODUCTION}

Population ageing is a common phenomenon in the world. ${ }^{1}$ Globally, the number of the oldest-old persons (aged 80 years or over ${ }^{2}$ is projected to triple between 2019 and 2050, growing from 143 million to 426 million. ${ }^{1}$ In China, the number of the oldest-old persons will increase more than fourfold between
Strengths and limitations of this study

- Evaluating the prevalence of hyperuricaemia among the oldest-old persons in Southwestern China can provide information on achieving healthy ageing in China.

- Guided by the recently proposed definition of hyperuricaemia addressing the subject of the negative impact of serum uric acid on the cardiovascular system, a $5.6 \mathrm{mg} / \mathrm{dL}$ cut-off was adopted to define hyperuricaemia and compared with the classic cut-off, which may provide reference for future hyperuricaemia-related studies.

- The rural setting of the study may compromise the representativeness of the sample.

2019 and 2050, growing from 26.1 million to reach 115.3 million, projected by the Population Division of the Department of Economic and Social Affairs of the United Nations. ${ }^{3}$ Healthy ageing is an imperative strategy to deal with population ageing.

Hyperuricaemia is a metabolic disease due to the overproduction or underexcretion of uric acid (UA), a natural product generated from the purine metabolism. ${ }^{45}$ The burden of hyperuricaemia is substantial both in developing and developed countries. The 2015-2016 National Health and Nutrition Examination Survey found that the prevalence of hyperuricaemia in the USA was $20.1 \%$, approximately 47.13 million adults with hyperuricaemia. ${ }^{6}$ Data from the National Kidney Disease Surveillance Programme indicated that the prevalence of hyperuricaemia in the Irish was $24.5 \%$ in 2014 , a pattern of increasing prevalence from 2006 to $2014 .^{7}$ In the 2009-2010, China National Survey of Chronic Kidney Disease, the prevalence of hyperuricaemia was $8.4 \%$, corresponding to a total of 92.9 million adults affected. ${ }^{8}$ Furthermore, the prevalence of hyperuricaemia 
increased with advancing age, and the highest prevalence was observed in the oldest-old persons. ${ }^{67}$

Thus, it is extremely significant to explore the prevalence of hyperuricaemia and associated factors in the oldest-old population. Although previous studies have reported that elevated serum UA (SUA) or hyperuricaemia is positively associated with atrial fibrillation, ${ }^{9}$ vascular inflammation, ${ }^{10}$ coronary artery disease, ${ }^{11}$ better muscle function ${ }^{12}$ in the oldest-old population, less evidence on the prevalence of hyperuricaemia among the oldest-old persons in China is known, with only one including 966 centenarians and 788 near-centenarians in the China Hainan Centenarian Cohort Study. ${ }^{13}$ Therefore, we conducted a community-based cross-sectional study to investigate the prevalence of hyperuricaemia among the oldest-old persons in Chengdu and identify associated factors to provide information on achieving healthy ageing in China.

\section{METHODS}

\section{Study area}

Chengdu is the capital city of Sichuan province, located at $30^{\circ} 05^{\prime}-31^{\circ} 26^{\prime} \mathrm{N}$ and $102^{\circ} 54^{\prime}-104^{\circ} 53^{\prime} \mathrm{E}$. Chengdu is the fourth-largest city in China, the very centre of commerce, logistics, finance and science and technology, and the hub of transport and communication in Western China. The regional gross domestic product (GDP) of the city achieved 1701.265 billion in 2019, with an increase of $7.8 \%$. The total resident population is more than 16 million in 2019, one of the most densely populated cities in China. Jinjiang, Qingyang, Longquanyi is located in the southeast, the northwest, and the east of Chengdu, respectively, which can be representative of the urban areas in Chengdu.

\section{Participants}

As described in detail previously, ${ }^{14}$ a community-based cross-sectional study was conducted in urban areas of Chengdu, China, from September 2015 to June 2016. Survey participants were randomly recruited using a multistage stratified cluster sampling method. ${ }^{14}$ A representative sample of 1391 people aged over 80 years were enrolled from three districts: Jinjiang, Qingyang, Longquanyi (figure 1). A total of 145 participants were excluded due to unwillingness, severe neurological and psychological diseases, including Alzheimer's disease, renal failure, end-stage cancer and severe frailty. This study consisted of three sections: a structured questionnaire, anthropometric measurements and laboratory tests. We excluded participants who had missing demographic information or fasting blood glucose, lipids and so on $(n=65)$, and those whose SUA concentrations were missing $(n=41)$. Subsequently, a total of 1285 participants were analysed in this study. Written informed consent was obtained from all subjects.

\section{Data collection}

As described in detail previously, ${ }^{14}$ data collection was completed by more than 20 trained medical staff in this study. Demographic factors (eg, age and sex), health-risky behaviours (eg, smoking and drinking) and personal medical history (eg, the doctor's diagnosis or meditation of hypertension) were collected using a self-reported questionnaire. Anthropometric data, blood pressure, blood biomarkers were collected using the standard examination. Body mass index (BMI, $\mathrm{kg} / \mathrm{m}^{2}$ ) was calculated as weight $(\mathrm{kg})$ divided by height $(\mathrm{m})$ squared. Blood pressure was measured three times using standardised mercury sphygmomanometers. Using venous blood samples, total cholesterol (TC), triglycerides (TG) were measured by oxidase method, and blood glucose was measured by glucose oxidase method, and UA was measured by the phosphotungstic acid method in the Clinical Laboratory Center of the Second People's Hospital of Chengdu.

\section{Variable measure}

Smoking status and drinking status were clarified as 'never' or 'former and current'. Due to changes in body composition with ageing, overweight was defined as BMI $>27 \mathrm{~kg} / \mathrm{m}^{2}$, acclaimed for the elderly ( $\geq 60$ years). ${ }^{15}$ Hyperuricaemia was defined as SUA $>420 \mu \mathrm{mol} / \mathrm{L}$ in men or SUA $>360 \mu \mathrm{mol} / \mathrm{L}$ in women, according to Dietary guide for hyperuricaemia and gout patients (Chinese standard, WS/T 560-2017). Recent evidence suggested $5 \mathrm{mg} / \mathrm{dL}(333 \mu \mathrm{mol} / \mathrm{L})$ was a more appropriate cut-off of SUA when investigating the negative impact of SUA on the cardiovascular system. ${ }^{16}$ For a comparison, hyperuricaemia was also defined as SUA $>333 \mu \mathrm{mol} / \mathrm{L}$ (5.6 mg/ $\mathrm{dL}$ ) for both males and females. Hypertension was defined as systolic blood pressure (SBP) $\geq 140 \mathrm{~mm} \mathrm{Hg}$ and (or) diastolic blood pressure (DBP) $\geq 90 \mathrm{~mm} \mathrm{Hg}$ or the selfreported history or meditation of hypertension. Diabetes was defined as fasting blood glucose $\geq 7.0 \mathrm{mmol} / \mathrm{L}$ and (or) oral glucose tolerance test (OGTT) 2-hour postload glucose $\geq 11.1 \mathrm{mmol} / \mathrm{L}$ or the self-reported history or meditation of diabetes. Dyslipidaemia was defined as $\mathrm{TC} \geq 6.2 \mathrm{mmol} / \mathrm{L}$, and/or low-density lipoprotein cholesterol (LDL-C) $\geq 4.1 \mathrm{mmol} / \mathrm{L}$, and/or high-density lipoprotein cholesterol (HDL-C) $<1.0 \mathrm{mmol} / \mathrm{L}$, and/ or TG $\geq 2.3 \mathrm{mmol} / \mathrm{L}$, and/or the self-reported history or meditation of dyslipidaemia, based on the Chinese guidelines for the management of dyslipidaemia in adults. ${ }^{17}$ History of kidney disease was defined as the self-reported of the doctor's diagnosis of kidney disease, including glomerulonephritis, pyelonephritis, hypertensive nephropathy, diabetic nephropathy, obstructive nephropathy, drug-induced nephropathy. A summary table was reported in online supplemental table 1 .

\section{Statistical analysis}

All statistical analyses were performed while using Statistical Product and Service Solutions (SPSS, V.23.0). Categorical variables, including sex, smoking, drinking, hypertension, diabetes mellitus, dyslipidaemia and kidney disease, were presented as absolute numbers with the percentage, and Pearson's $\chi^{2}$ test was used to detect 


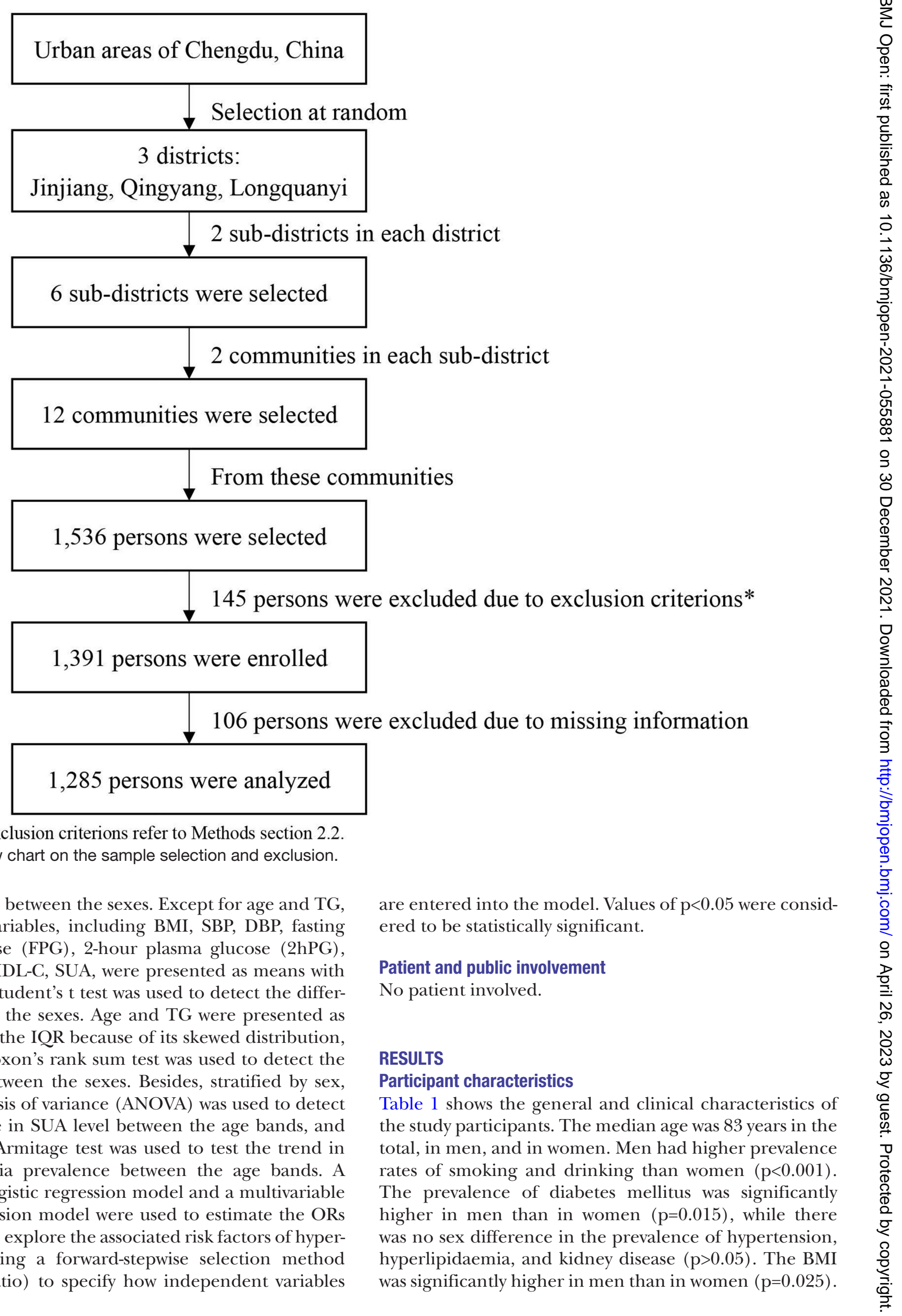


Table 1 General and clinical characteristics of the study participants

\begin{tabular}{lcccc}
\hline & $\begin{array}{l}\text { Overall } \\
(\mathbf{n}=\mathbf{1 2 8 5})\end{array}$ & $\begin{array}{l}\text { Male } \\
(\mathbf{n}=626)\end{array}$ & $\begin{array}{l}\text { Female } \\
(\mathbf{n}=659)\end{array}$ & P value \\
\hline Age (years) & $83(81-86)$ & $83(81-86)$ & $83(81-85)$ & 0.217 \\
\hline Former or current smoking & $370(28.8 \%)$ & $279(44.6 \%)$ & $91(13.8 \%)$ & $<0.001$ \\
\hline Former or current drinking & $214(16.7 \%)$ & $180(28.8 \%)$ & $34(5.2 \%)$ & $<0.001$ \\
\hline Hypertension & $940(73.2 \%)$ & $457(73.0 \%)$ & $483(73.3 \%)$ & 0.841 \\
\hline Diabetes mellitus & $350(27.2 \%)$ & $190(30.4 \%)$ & $160(24.3 \%)$ & 0.015 \\
\hline Hyperlipidaemia & $378(29.4 \%)$ & $171(27.3 \%)$ & $207(31.4 \%)$ & 0.107 \\
\hline Kidney disease & $31(2.4 \%)$ & $13(2.1 \%)$ & $18(2.7 \%)$ & 0.445 \\
\hline BMI $\left(\mathrm{kg} / \mathrm{m}^{2}\right)$ & $23.0 \pm 3.9$ & $23.3 \pm 3.6$ & $22.8 \pm 4.1$ & 0.025 \\
\hline SBP $(\mathrm{mm} \mathrm{Hg})$ & $149.5 \pm 21.7$ & $147.4 \pm 20.1$ & $151.5 \pm 22.9$ & 0.001 \\
\hline DBP $(\mathrm{mm} \mathrm{Hg})$ & $74.1 \pm 12.0$ & $74.5 \pm 11.3$ & $73.7 \pm 12.6$ & 0.279 \\
\hline FPG $(\mathrm{mmol} / \mathrm{L})$ & $5.6 \pm 2.1$ & $5.7 \pm 2.2$ & $5.5 \pm 2.0$ & 0.092 \\
\hline 2hPG $(\mathrm{mmol} / \mathrm{L})$ & $8.6 \pm 3.7$ & $8.7 \pm 2.7$ & $8.4 \pm 4.4$ & 0.260 \\
\hline TG $(\mathrm{mmol} / \mathrm{L})$ & $1.21(0.91-1.64)$ & $1.15(0.85-1.64)$ & $1.25(0.95-1.70)$ & $<0.001$ \\
\hline TC $(\mathrm{mmol} / \mathrm{L})$ & $4.81 \pm 0.92$ & $4.57 \pm 0.85$ & $5.04 \pm 0.93$ & $<0.001$ \\
\hline LDL-C $(\mathrm{mmol} / \mathrm{L})$ & $2.61 \pm 0.75$ & $2.47 \pm 0.71$ & $2.74 \pm 0.76$ & $<0.001$ \\
\hline HDL-C $(\mathrm{mmol} / \mathrm{L})$ & $1.62 \pm 0.42$ & $1.54 \pm 0.41$ & $1.70 \pm 0.43$ & $<0.001$ \\
\hline SUA $(\mu \mathrm{mol} / \mathrm{L})$ & $334.6 \pm 117.7$ & $360.0 \pm 118.3$ & $310.4 \pm 111.9$ & $<0.001$ \\
\hline
\end{tabular}

Data are presented as mean $\pm \mathrm{SD}, \mathrm{n}(\%)$; Age and TG were reported as median (IQR).

$\mathrm{BMI}$, body mass index; DBP, diastolic blood pressure; FPG, fasting plasma glucose; HDL-C, high-density lipoprotein cholesterol; 2hPG, 2hour plasma glucose; LDL-C, low-density lipoprotein cholesterol; SBP, systolic blood pressure; SUA, serum uric acid; TC, total cholesterol; TG, triglyceride.

Men had lower SBP than women $(\mathrm{p}=0.001)$, although there was no sex difference in DBP $(p>0.05)$. Moreover, there was no sex difference in the FPG level and 2hPG level $(p>0.05)$. However, men had lower TG, TC, LDL-C, HDL-C than women $(p<0.001)$. The SUA level was significantly higher in men than in women $(\mathrm{p}<0.001)$.

\section{SUA level and hyperuricaemia}

Men affected with hyperuricaemia $(484.4+71.1 \mu \mathrm{mol} / \mathrm{L})$ had higher level of SUA than healthy men $(309.1+93.5 \mu \mathrm{mol} / \mathrm{L}, \quad \mathrm{p}<0.001)$, and women affected with hyperuricaemia $(424.4+61.9 \mu \mathrm{mol} / \mathrm{L})$ had higher level of SUA than healthy women $(261.4+91.1 \mu \mathrm{mol} / \mathrm{L}$, $\mathrm{p}<0.001)$. Figure $2 \mathrm{~A}$ shows the age-specific SUA level. The mean SUA level in men was $357.8 \mu \mathrm{mol} / \mathrm{L}(\mathrm{SD}=110.9)$ for aged $80-84$ years, $363.7 \mu \mathrm{mol} / \mathrm{L}(\mathrm{SD}=138.2)$ for

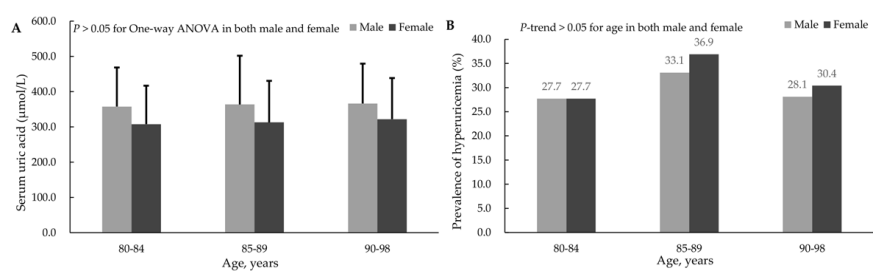

Figure 2 Age-specific serum uric acid level and prevalence of hyperuricaemia among the oldest-old in Southwestern China. (A) Age-specific serum uric acid level in males and females; (B) prevalence of hyperuricaemia in each age and gender group. ANOVA, analysis of variance. aged 85-89 years, $366.5 \mu \mathrm{mol} / \mathrm{L}(\mathrm{SD}=113.1)$ for aged 90-98 years, respectively. In women, the mean SUA level was $307.7 \mu \mathrm{mol} / \mathrm{L} \quad(\mathrm{SD}=109.2)$ for aged $80-84$ years, $312.9 \mu \mathrm{mol} / \mathrm{L}(\mathrm{SD}=117.9)$ for aged $85-89$ years, $321.8 \mu \mathrm{mol} / \mathrm{L}(\mathrm{SD}=116.7)$ for aged $90-98$ years, respectively. There was no statistical significance in the SUA level between the age bands among men and women ( $p>0.05)$. In addition, the prevalence of hyperuricaemia among the oldest-old was $29.6 \%$ in the total, $29.1 \%$ in men, $30.0 \%$ in women, respectively, and there was no sex difference $(p>0.05)$. Figure $2 B$ shows the age-specific prevalence of hyperuricaemia. Among men, 27.7\% (114/412) of aged $80-84$ years, $33.1 \%(52 / 157)$ of aged $85-89$ years, $28.1 \%$ $(16 / 57)$ of aged $90-98$ years had hyperuricaemia. $27.7 \%$ $(122 / 441)$ of aged $80-84$ years, $36.9 \%(55 / 149)$ of aged $85-89$ years, $30.4 \%(21 / 69)$ of aged $90-98$ years had hyperuricaemia in women. There was no increasing trend of hyperuricaemia prevalence between the age bands $(\mathrm{p}=0.483$ in men; $\mathrm{p}=0.175$ in women). With a recently proposed definition of hyperuricaemia, the prevalence of hyperuricaemia among the oldest-old was $50.4 \%$ in the total, $62.6 \%$ in men, $38.8 \%$ in women, respectively, and men had a higher prevalence of hyperuricaemia than women $(p<0.001)$. The prevalence of hyperuricaemia decreased with advanced age in men $(p=0.00 .025$, (online supplemental figure 1). 
Table 2 Comorbidities of hyperuricaemia among the study participants by sex

\begin{tabular}{|c|c|c|c|c|}
\hline \multirow[b]{2}{*}{ Comorbidity } & \multicolumn{2}{|l|}{ Male } & \multicolumn{2}{|l|}{ Female } \\
\hline & Hyperuricaemia & Normal & Hyperuricaemia & Normal \\
\hline Hypertension & $142(78.0)$ & $315(70.9)^{*}$ & $153(77.3)$ & 330 (71.6) \\
\hline Hyperlipidaemia & 69 (37.9) & $102(23.0)^{*}$ & $82(41.4)$ & $125(27.1)^{*}$ \\
\hline Overweight & $31(17.0)$ & $32(7.2)^{\star}$ & 58 (29.3) & $53(11.5)^{\star}$ \\
\hline
\end{tabular}

Data are presented as $\mathrm{n}(\%)$.

${ }^{*} \mathrm{P}<0.05$.

\section{Comorbidities of hyperuricaemia}

Among men affected with hyperuricaemia (table 2), $78.0 \%, 30.8 \%, 37.9 \%, 17.0 \%$ had hypertension, diabetes mellitus, hyperlipidaemia and overweight, respectively. Men affected with hyperuricaemia had higher prevalence of hypertension, hyperlipidaemia and overweight than the normal level of SUA ( $p<0.05) .77 .3 \%, 36.9 \%, 41.4 \%$, $29.3 \%$ of women with hyperuricaemia had hypertension, diabetes mellitus, hyperlipidaemia and overweight, respectively. Women affected with hyperuricaemia had a higher prevalence of diabetes mellitus, hyperlipidaemia and overweight than the normal level of SUA $(p<0.05)$. With a recently proposed definition of hyperuricaemia, very similar results were reported in online supplemental table 2.

\section{Associated factors of hyperuricaemia}

Table 3 shows the ORs for hyperuricaemia using the univariable and multivariable logistic regression analyses. In the univariable logistic regression analysis (model 1), hypertension, hyperlipidaemia and overweight were positively associated with hyperuricaemia in men. Age, diabetes mellitus, hyperlipidaemia and overweight were positively associated with hyperuricaemia in women. In the multivariable logistic regression analysis (model 2), hyperlipidaemia and overweight were positively associated with the risk of hyperuricaemia in men. Compared with participants aged $80-84$ years, those aged $85-89$ years had a higher risk of hyperuricaemia in women. Besides, diabetes mellitus, hyperlipidaemia and overweight were positively associated with the risk of hyperuricaemia in women. Logistic regression analyses using a recently proposed definition of hyperuricaemia delivered similar results (online supplemental table 3).

\section{DISCUSSION}

In this representative sample of the community-based population in Chengdu, we observed a substantial burden of hyperuricaemia in the urban oldest-old. Specifically, the overall prevalence of hyperuricaemia was $29.6 \%$. There was no significant sex difference in the prevalence of hyperuricaemia, $29.1 \%$ in men vs $30.0 \%$ in women.

Table 3 ORs for hyperuricaemia among the study participants by sex

\begin{tabular}{|c|c|c|c|c|}
\hline & \multicolumn{2}{|l|}{ Male } & \multicolumn{2}{|l|}{ Female } \\
\hline & Model 1 & Model 2 & Model 1 & Model 2 \\
\hline \multicolumn{5}{|l|}{ Age groups } \\
\hline 85-89 years & $1.30(0.87-1.92)$ & - & $1.53(1.03-2.27)^{\star}$ & $1.80(1.19-2.73)^{\star}$ \\
\hline 90-98 years & $1.02(0.55-1.89)$ & - & $1.14(0.66-1.99)$ & $1.70(0.94-3.07)$ \\
\hline Former or current drinking & $1.15(0.79-1.67)$ & - & $0.83(0.38-1.81)$ & - \\
\hline Hypertension & $1.56(1.03-2.36) \dagger$ & - & $1.29(0.87-1.90)$ & - \\
\hline Diabetes mellitus & $1.03(0.71-1.50)$ & - & $2.51(1.73-3.64)^{\star}$ & $1.99(1.34-2.97)^{\star}$ \\
\hline Hyperlipidaemia & $2.05(1.41-2.97) \dagger$ & $1.86(1.27-2.72) \dagger$ & $1.90(1.34-2.70)^{*}$ & $1.78(1.23-2.58)^{\star}$ \\
\hline Kidney disease & $2.92(0.97-8.81)$ & - & $1.17(0.43-3.16)$ & - \\
\hline
\end{tabular}

Data are presented as odds ratios $(95 \% \mathrm{Cl})$. Model 1 was a univariable logistic regression model. Model 2 was a multivariable logistic regression model, using a forward-stepwise selection method (likelihood ratio) to specify how independent variables are entered into the model.

${ }^{*} \mathrm{P}<0.05$.

†For missing values, we created a dump variable for missing values. 
Using a recently proposed cut-off of SUA, identified as that above which cardiovascular mortality significantly, ${ }^{16}$ the prevalence of hyperuricaemia among the urban oldest-old population was $50.4 \%$. Multivariable analyses found that hyperlipidaemia and overweight were associated with the risk of hyperuricaemia in the oldest-old population, regardless of sex. Furthermore, there was a significant association between diabetes mellitus and hyperuricaemia only in women, but not in men.

In this study, our estimated prevalence of hyperuricaemia among the oldest-old is approximate to the Chinese centenarians and near-centenarians $(29.02 \%)^{13}$, remarkably more than that from adults aged 18 years and older in the 2009-2010 China National Survey of Chronic Kidney Disease $(8.4 \%){ }^{8}$ It has been reported that the prevalence of hyperuricaemia is highest in the oldest-old population, $27.8 \%$ in the USA, ${ }^{6} 43.0 \%$ in the Irish. ${ }^{7}$ Differences in the prevalence of hyperuricaemia among the oldest-old may be accounted for the race, region, dietary habits. ${ }^{6713}$ Higher Seafood consumption, higher meat consumption and lower vegetable consumption were significantly associated with the increasing risk of hyperuricaemia among the centenarians and near-centenarians. ${ }^{13}$

Of note, the prevalence of hyperuricaemia defined by a recently proposed cut-off of SUA $(5.6 \mathrm{mg} / \mathrm{dL})$ was $70.3 \%$ higher than that in the classic definition $(7.0 \mathrm{mg} /$ $\mathrm{dL}$ in men and $6.0 \mathrm{mg} / \mathrm{dL}$ in women), consistent with a previous study. ${ }^{18}$ A $5.6 \mathrm{mg} / \mathrm{dL}$ was identified as a higher risk of cardiovascular mortality among Italians, ${ }^{16}$ more multicentre and multiethnic prospective studies are needed to prove external validity in health outcomes.

Previous studies have shown the higher prevalence of hyperuricaemia among adults in men than in women. ${ }^{819-21}$ However, our study indicated no difference in the prevalence of hyperuricaemia among the oldest-old between men and women. Young women adults with a lower prevalence of hyperuricaemia can be explained by the uricosuric effects of oestrogen.$^{22-24}$ Following menopause, the prevalence of hyperuricaemia rose sharply in older women. ${ }^{722} 23$ The effect of oestrogen disappeared in the oldest-old women, which may account for no sex difference in the prevalence of hyperuricaemia.

Our findings appear in agreement with a previous study in China, where the positive association between high TG and hyperuricaemia among the oldest-old was observed in both men and women. ${ }^{25}$ Moreover, overweight was positively associated with the prevalence of hyperuricaemia in the oldest-old, consistent with a study among long-lived Chinese subjects aged 90 years and older, indicating that higher levels of SUA may be positively associated with higher BMI. ${ }^{26}$ Besides, diabetes mellitus was associated with an increased prevalence of hyperuricaemia only in women. Nevertheless, evidence from observational studies can be biased by potential confounding factors and reverse causality. Thus, high-quality studies such as Mendelian randomisation studies should be carried out to confirm whether there is a causal association between cardiovascular disease risk factors and hyperuricaemia in the oldest-old population.

Our studies have several limitations. First, the definition of hyperuricaemia merely relied on the concentration of SUA. Medication information (eg, diuretic) ${ }^{27}$ that may affect the level of SUA was not available, which can cause the estimated prevalence of hyperuricaemia subject to error. Second, potential confounding factors such as dietary intakes were not included. Third, kidney disease was defined by a self-reported history, rather than estimated glomerular filtration rate, which might cause a false-negative result. ${ }^{28}$ Moreover, all participants were recruited from the urban oldest-old population, so the results may not be generalisable to the rural oldest-old population. Finally, the association observed in this study resulted from a cross-sectional study, which may suffer from potential biases and reverse causality. Thus, more prospective studies or Mendelian Randomisation studies are needed to determine causality. Notably, this is the first comprehensive study that accurately evaluated the prevalence of hyperuricaemia among the oldest-old persons in Southwestern China, and identified factors associated with hyperuricaemia.

In conclusion, this study demonstrated that the burden of hyperuricaemia is substantial among the oldest-old population in the urban areas of Chengdu, China. Hyperlipidaemia and overweight are associated with the increasing prevalence of hyperuricaemia in both sexes, but the association between diabetes mellitus and hyperuricaemia is observed only in women. Further studies should be carried out to confirm the causal association.

\section{Author affiliations}

${ }^{1}$ Department of Geriatric Medicine, Inner Mongolia People's Hospital, Hohhot, Inner Mongolia, China

${ }^{2}$ Department of Epidemiology and Health Statistics, West China School of Public Health and West China Fourth Hospital, Sichuan University, Chengdu, Sichuan, China ${ }^{3}$ Department of Hematology and Rheumatology, Chengdu Second People's Hospital, Chengdu, Sichuan, China

${ }^{4}$ Department of Cardiology, Chengdu Second People's Hospital, Chengdu, Sichuan, China

${ }^{5}$ Department of Endocrinology and Metabolism, Chengdu Second People's Hospital, Chengdu, Sichuan, China

${ }^{6}$ Stroke Center, Chengdu Second People's Hospital, Chengdu, Sichuan, China ${ }^{7}$ School of Health Policy and Management, Nanjing Medical University, Nanjing, Jiangsu, China

Correction notice This article has been corrected since it first published. Author 'Wei-Wei Tang' has been added as the corresponding author.

Acknowledgements We sincerely thank all the staff and participants for their immense contributions.

Contributors $\mathrm{X}-\mathrm{JC}$ and WZ conceived and designed the study, performed statistical analyses and drafted the manuscript. R-LY, X-BH, YL, R-HX and DW participated in the field investigation and data checking. X-BH and W-WT advised on the interpretation of results and were responsible for the overall research content. All authors read and approved the final manuscript.

Funding This study is supported by the health projects of Chengdu Municipal Science and Technology Bureau (10YTYB272SF-182, 2014-HM01-00357-SF).

Disclaimer The funding bodies have no role in the design of the study and collection, analysis, interpretation of data and in writing the manuscript.

Competing interests The authors declare that they have no competing interests. 
Patient consent for publication Not applicable.

Ethics approval This study was approved by the ethics committee of the Second People's Hospital of Chengdu (No. 2015030).

Provenance and peer review Not commissioned; externally peer reviewed.

Data availability statement Data are available in a public, open access repository. All data are fully available from the corresponding author on reasonable request.

Supplemental material This content has been supplied by the author(s). It has not been vetted by BMJ Publishing Group Limited (BMJ) and may not have been peer-reviewed. Any opinions or recommendations discussed are solely those of the author(s) and are not endorsed by BMJ. BMJ disclaims all liability and responsibility arising from any reliance placed on the content. Where the content includes any translated material, BMJ does not warrant the accuracy and reliability of the translations (including but not limited to local regulations, clinical guidelines, terminology, drug names and drug dosages), and is not responsible for any error and/or omissions arising from translation and adaptation or otherwise.

Open access This is an open access article distributed in accordance with the Creative Commons Attribution Non Commercial (CC BY-NC 4.0) license, which permits others to distribute, remix, adapt, build upon this work non-commercially, and license their derivative works on different terms, provided the original work is properly cited, appropriate credit is given, any changes made indicated, and the use is non-commercial. See: http://creativecommons.org/licenses/by-nc/4.0/.

\section{ORCID iD}

Xiao-Bo Huang http://orcid.org/0000-0002-4692-1433

\section{REFERENCES}

1 United Nations, Department of Economic and Social Affairs, Population Division. World Population Ageing 2019 [article online], 2020. Available: https://www.un.org/en/development/desa/ population/publications/pdf/ageing/WorldPopulationAgeing2019Report.pdf [Accessed 26 Jun 2020].

2 United Nations, Department of Economic and Social Affairs, Population Division. World population ageing 2015, 2015. Available: https://www.un.org/en/development/desa/population/publications/ pdf/ageing/PopulationAgeingAndDevelopment2015.pdf [Accessed 26 Jun 2020].

3 United Nations, Department of Economic and Social Affairs, Population Division. Data from: world population prospects 2019, 2019. Available: https://population.un.org/wpp/Download/ Files/1_Indicators\%20(Standard)/CSV_FILES/WPP2019_ PopulationByAgeSex Medium.csv

4 Ichida K, Matsuo H, Takada T, et al. Decreased extra-renal urate excretion is a common cause of hyperuricemia. Nat Commun 2012;3:764.

5 Dalbeth N, Merriman TR, Stamp LK. Gout. The Lancet 2016;388:2039-52.

6 Chen-Xu M, Yokose C, Rai SK, et al. Contemporary prevalence of gout and hyperuricemia in the United States and Decadal trends: the National health and nutrition examination survey, 2007-2016. Arthritis Rheumatol 2019;71:991-9.

7 Kumar A. U. A, Browne LD, Li X, et al. Temporal trends in hyperuricaemia in the Irish health system from 2006-2014: a cohort study. PLoS One 2018;13:e0198197.

8 Liu H, Zhang X-M, Wang Y-L, et al. Prevalence of hyperuricemia among Chinese adults: a national cross-sectional survey using multistage, stratified sampling. J Nephrol 2014;27:653-8.
9 Huang G, Xu R-H, Xu J-B, et al. Hyperuricemia is associated with atrial fibrillation prevalence in very elderly - a community based study in Chengdu, China. Sci Rep 2018;8:12403.

10 Malik R, Aneni EC, Shahrayar S, et al. Elevated serum uric acid is associated with vascular inflammation but not coronary artery calcification in the healthy octogenarians: the Brazilian study on healthy aging. Aging Clin Exp Res 2016;28:359-62.

11 Sun $\mathrm{Y}$, Zhang $\mathrm{H}$, Tian W, et al. Association between serum uric acid levels and coronary artery disease in different age and gender: a cross-sectional study. Aging Clin Exp Res 2019;31:1783-90.

12 Molino-Lova R, Sofi F, Pasquini G, et al. Higher uric acid serum levels are associated with better muscle function in the oldest old: results from the Mugello study. Eur J Intern Med 2017;41:39-43.

13 Han Q-X, Zhang D, Zhao Y-L, et al. Risk Factors For Hyperuricemia In Chinese Centenarians And Near-Centenarians]]\&gt. Clinical interventions in aging 2019;14:2239-47.

14 Liang B, Tang WW, Zhang WQ, et al. Prevalence and associated factors of diabetes mellitus in a very elderly Chinese population: a cross-sectional study. Biomed Environ Sci 2020;33:315-22.

15 Lipschitz DA. Screening for nutritional status in the elderly. Prim Care 1994;21:55-67.

16 Virdis A, Masi S, Casiglia E, et al. Identification of the uric acid thresholds predicting an increased total and cardiovascular mortality over 20 years. Hypertension 2020;75:302-8.

17 Joint committee for guideline revision. 2016 Chinese guidelines for the management of dyslipidemia in adults. $J$ Geriatr Cardiol 2018;15:1-29.

18 Maloberti A, Qualliu E, Occhi L, et al. Hyperuricemia prevalence in healthy subjects and its relationship with cardiovascular target organ damage. Nutrition, Metabolism and Cardiovascular Diseases 2021;31:178-85.

19 Song P, Wang H, Xia W, et al. Prevalence and correlates of hyperuricemia in the middle-aged and older adults in China. Sci Rep 2018;8:4314.

20 Trifirò G, Morabito P, Cavagna L, et al. Epidemiology of gout and hyperuricaemia in Italy during the years 2005-2009: a nationwide population-based study. Ann Rheum Dis 2013;72:694-700.

21 Zhu Y, Pandya BJ, Choi HK. Prevalence of gout and hyperuricemia in the US general population: the National health and nutrition examination survey 2007-2008. Arthritis Rheum 2011;63:3136-41.

22 Kuo C-F, Grainge MJ, Zhang W, et al. Global epidemiology of gout: prevalence, incidence and risk factors. Nat Rev Rheumatol 2015;11:649-62.

23 Johnson RJ, Bakris GL, Borghi C, et al. Hyperuricemia, acute and chronic kidney disease, hypertension, and cardiovascular disease: report of a scientific workshop organized by the National kidney Foundation. Am J Kidney Dis 2018;71:851-65.

24 Cho SK, Winkler CA, Lee S-J, et al. The prevalence of hyperuricemia sharply increases from the late menopausal transition stage in middle-aged women. J Clin Med 2019;8:296.

25 Zhang L, Wan Q, Zhou Y, et al. Age-related and gender-stratified differences in the association between high triglyceride and risk of hyperuricemia. Lipids Health Dis 2019;18.

26 Yue J-R, Huang C-Q, Dong B-R. Association of serum uric acid with body mass index among long-lived Chinese. Exp Gerontol 2012;47:595-600.

27 Maloberti A, Bombelli M, Facchetti R, et al. Relationships between diuretic-related hyperuricemia and cardiovascular events: data from the uric acid right for heArt health study. $J$ Hypertens 2021;39:333-40.

28 Russo E, Viazzi F, Pontremoli R, et al. Association of uric acid with kidney function and albuminuria: the uric acid right for heArt health (URRAH) project. J Nephrol 2021;359. 